\title{
Notes on Babies in Leper Colonies.
}

\section{M. Russell.}

[Mrs. Russell has kindly furnished the following notes on a crèche for babies separated at birth from their leper mothers. This crèche was begun by Mrs. Brown, wife of the late superintendent of the Uzuakoli Leper Settlement. The results have been very successful, and the notes by Mrs. Russell, who is now in charge, will be found useful by those who purpose forming similar crèches.]

The house at Uzuakoli is in most respects ideal. It is built of cement, about 60 by $20 \mathrm{ft}$. and about $9 \mathrm{ft}$. high. A veranda about $6 \mathrm{ft}$. wide runs the whole length of the front. There are two doors in front and one behind, and windows, 9 in all, except at one end. These are provided with excellent lattice shutters which keep out rain and wind but allow plentiful ventilation. In front is a garden, partly grass and partly sand. The addition of 8 or $10 \mathrm{ft}$. of cement to the ground immediately in front of the veranda would be a great convenience, as will the shade from two orange trees planted at the outer corners of the garden. Behind the house are a mud-built kitchen with store-room adjoining, the latter containing a food-safe.

I regard as an important, indeed necessary, addition to any quarters for babies an isolation-room large enough to accommodate, say, three cots placed not too close together. 
Its windows and its broad yeranda must be completely protected by wire gauze to prevent flies and mosquitoes from gaining an entrance. There should be double doors, with a space of about $4 \mathrm{ft}$. between the two, and when the room is in use, the table occupying this space will have upon it a basin of disinfectant with a towel hanging beside it. The room must contain a cupboard with complete separate equipment-blankets, hot water bottles, plates, mugs, bowl for washing-up, etc.

The ward at Uzuakoli contains 14 cots. $3 \frac{1}{2} \mathrm{ft}$. is sufficient length for a cot-3 $\mathrm{ft}$. for some. The mosquito-nets should be long enough to reach the ground with two or three inches to spare, for a net cannot be tucked in as under a mattress. It is best to make the cots of very smooth, hard wood as this will better resist the onslaught of bugs. A bed, preferably an iron one, must be provided for the night-nurse.

As at Uzuakoli, there must be a roomy cupboard to hold spare blankets, clothing for cold weather, medicines, etc. etc.

Each cot has an under-blanket, a macintosh sheet and a blanket. Every baby past the bottle stage has a separate mug and a separate plate. This is very important, as it is not only hygienic but inculcates good manners and prevents the older infants from bolting their food and fighting over it, as is the case when a plate is shared.

The babies are weighed every week at the same hour and the results recorded in a book.

Small infants are fed every three hours, last feed 10 p.m. and first 6 a.m.

The meals for the one and two-year-olds are as follows :

6 a.m., 9 a.m., 3 p.m. and 6 p.m., 6 oz. milk.

7 a.m., usually a kind of porridge called Agedi made of maize flour, or rice and milk, E.G.

8 a.m., orange-juice. Usually about five oranges for 13 or 14 children.

11.30 a.m. Dinner of yam, or "foo-foo", or rice, with soup made of vegetables and meat or fish, palm-oil and Marmite. About twice a week very lightly-boiled eggs are stirred into the prepared food (usually rice) about $\frac{1}{2}$ egg for each child. This meal is followed by banana or paw-paw (mashed for the smallest children) or by $6 \mathrm{oz}$. milk.

4.30 p.m. As at 11.30, without the fruit.

Clothes are worn only on cold mornings and soon taken off as the day grows warmer. Little knitted vests are the most useful, but should be knitted of unshrinkable wool. In fine weather the children must be out in the sun between 7 and 11 a.m. and about 3 to bedtime at 5.30 . 
Doctor's inspection once a week after the weighing.

Bath morning and evening. Hands and faces washed before and after every meal.

It is important that there should be sufficient "jerries" of a small size to accommodate practically all children simultaneously. These should be ordered from England as small sizes are unobtainable in Nigeria.

All the cement flooring is washed with disinfectant daily, beds are washed all over as required, but at least once a week, also with disinfectant, and in fine weather they are all placed in the sun for some hours every day.

The staff of five nurses is assisted by two labourers who fetch wood and water, wash floors, and cots and blankets, etc.

Unexpected visits should be paid to the babies at all hours of the day and night. It is well to make sure by personal supervision that every important instruction is really carried out. If a nurse for example has been in the habit of using one tin of milk to make a feed for 8 children, if two more children are added, she will probably only take more water. Every detail of the children's lives must be constantly watched. 